\title{
Assessment of impact of climate change on productivity of tea (Camellia sinensis L.) plantations in Sri Lanka
}

\author{
M.A. Wijeratne ${ }^{i^{*}}$, A. Anandacoomaraswamy ${ }^{2}$, M.K.S.L.D. Amarathunga ${ }^{1}$, Janaka Ratnasiri ${ }^{3}$, \\ B.R.S.B. Basnayake ${ }^{4}$ and N. Kalra ${ }^{5}$ \\ Tea Research Institute of Sri Lanka, Low Country Station, Ratnapura. \\ Tea Research Institute of Sri Lanka, Talawakelle. \\ No. 27, Sudarshana Mawatha, Nawala, Rajagiriya. \\ Department of Meteorology, Bauddhaloka Mawatha, Colombo -07. \\ Indian Agricultural Research Institute, New Delhi-110012, India.
}

Revised: 15 March 2007; Accepted: 20 April 2007

\begin{abstract}
A study was undertaken to assess impact of climate change on productivity of tea lands in Sri Lanka. Findings of the study showed that tea cultivations at low and mid elevations are more vulnerable to adverse impacts of climate change than those at high elevations. The optimum temperature for tea cultivation was found to be about $22^{\circ} \mathrm{C}$. The study also indicated that reduction of monthly rainfall by $100 \mathrm{~mm}$ could reduce the productivity by $30-80 \mathrm{~kg}$ of 'made' tea $\mathrm{ha}^{-1}$. In different tea growing regions, the optimum rainfall for tea cultivation varied from 223 to $417 \mathrm{~mm}$ per month. Increase in ambient $\mathrm{CO}_{2}$ concentration from the present ambient level (around $370 \mathrm{ppm}$ ) to $600 \mathrm{ppm}$, increased the tea yield by about $33-37 \%$ depending on the elevation. Based on these estimated parameters, a simple crop model was developed for predicting tea yield under future climate scenarios. The model was incorporated into a special software package developed to assess impact of climate change on productivity of tea plantations. Yield projections by the crop model showed that rising temperatures and diminishing rainfall reduce tea yield in many tea growing regions except Wet zone Up country (WU). The results also predicted that tea yields are likely to increase at high elevations while the yields at low elevations are likely to reduce due to climate change. Hence, sustainable adaptation measures are proposed to minimize such adverse effects.
\end{abstract}

Key words: Climate change, $\mathrm{CO}_{2}$, crop model, productivity, tea

\section{INTRODUCTION}

Sri Lanka is a tropical country located within the Asiatic Monsoon Region. It receives most of its rainfall from the two monsoons i.e. South-West and the North-East. The average rainfall varies from below $1000 \mathrm{~mm}$ in the dry areas of the north-west and south east of the island to over $4000 \mathrm{~mm}$ at certain locations on the south-western slopes of the hills. Temperature varies with altitude. The mean temperature in the low lands is around $26.6-27.7^{\circ} \mathrm{C}$ and it decreases with altitude to around $15.5^{\circ} \mathrm{C}$ at Nuwara Eliya $(1890 \mathrm{~m})$. The majority of tea growing regions are located in the Wet Zone and some are found in the intermediate zone. The Sri Lanka Country Report on Climate Change ${ }^{1}$ has shown that the increase in temperature by 2070 will be in the range of $+0.4{ }^{\circ} \mathrm{C}$ to $+3.0^{\circ} \mathrm{C}$. As per the rainfall predictions, the Wet Zone will record $10 \%$ increase per year in both dry and wet seasons. Moreover, the $\mathrm{CO}_{2}$ level in the atmosphere is predicted to be approximately in the range of $600-700 \mathrm{ppm}$ by the year 2100 .

The average productivity of tea plantations in Sri Lanka has shown an overall increase since 1930s even though there have been fluctuations between years. Presently, the national production of tea generally expressed as the quantity of processed or 'made' tea, exceeds 300 million $\mathrm{kg}$ a year. The productivity of tea lands is known to be greatly influenced by rainfall and temperature. Previous studies have established strong relationships between the environmental factors and tea yield ${ }^{2-4}$. Some crop models have also been developed to predict tea yield under varying climatic conditions ${ }^{5}$. Increase in temperature and reduction in rainfall due to global warming could adversely affect the productivity and sustainability of tea plantations in the future ${ }^{1,6}$.Tea is considered to be one of the largest exchange earning

\footnotetext{
${ }^{*}$ Corresponding author
} 
industries in Sri Lanka, upon which a large number of families are dependent ${ }^{7}$. This is true for many other tea growing countries in the region. Therefore, it is essential to investigate the possible impact of climate change on productivity of tea lands and propose suitable adaptation measures to arrest any adverse impacts. Although there are dynamic and mathematical crop models to predict tea yield under varying climatic conditions, they do not include the influence of ambient $\mathrm{CO}_{2}$ on crop growth and yield. Taking these factors into consideration, a series of studies were conducted at the Tea Research Institute of Sri Lanka (TRI) in collaboration with the Meteorological Department to first develop climate change scenarios and then evaluate the impact of climate change on productivity of tea lands and propose suitable adaptation measures to minimize any adverse effects.

\section{METHODS AND MATERIALS}

Data collection: Tea plantations of Sri Lanka are found in several agro ecological regions with varying climatic and soil conditions extending from low elevations in the South West to elevations exceeding $2000 \mathrm{~m}$. In order to simplify the development of the crop model, temperature, rainfall, and $\mathrm{CO}_{2}$ were selected as the climatic factors determining productivity. Accordingly, productivity and rainfall data for the period of 1976-1995 were collected from 25 tea estates from five main agro ecological regions i.e. 4 estates from Wet zone Up country WU; 4 estates from Intermediate zone Up country (IU), 7 estates from Wet zone Mid country (WM) and 8 estates from Wet zone Low country (WL). As there were very few estates in the Intermediate zone Mid country (IM), only two estates were selected. These estates were selected based on the extent of tea cultivation in the region and availability of both rainfall and productivity data for the period of 19761995. The temperature and rainfall records of the meteorological stations located in four regions (excluding IM) were obtained and the averaged values over the baseline period 1961-1990 are given in Table 1.

Table 1: Base Line Climate (Mean maximum and minimum temperatures and annual rainfall) at four locations representing Wet zone Low country-WL, Wet zone mid country-WM, Wet zone Up country-WU and Intermediate zone Up country-IU

\begin{tabular}{lccc}
\hline Location & $\begin{array}{c}\text { Maximum } \\
\left({ }^{\circ} \mathrm{C}\right)\end{array}$ & $\begin{array}{c}\text { Minimum } \\
\left({ }^{\circ} \mathrm{C}\right)\end{array}$ & $\begin{array}{c}\text { Rainfall } \\
(\mathrm{mm})\end{array}$ \\
\hline Ratnapura (WL) & 32.0 & 22.9 & 3617 \\
Kandy (WM) & 29.0 & 20.2 & 1863 \\
NuwalaEliya (WU) & 20.5 & 11.5 & 1907 \\
Passara (IU) & 28.7 & 18.5 & 1777 \\
\hline
\end{tabular}

Field experiment on $\mathrm{CO} 2$ fertilization: Two field experiments were conducted at high elevation (Tea Research Institute, Talawakelle, $1380 \mathrm{~m}$ amsl) and low elevation (Tea Research Institute, Ratnapura, $60 \mathrm{~m}$ amsl) to study the effect of $\mathrm{CO}_{2}$ enrichment on yield of tea. The open-top chambers, each measuring $3.6 \mathrm{~m} \times 1.2 \mathrm{~m}$ were fabricated for this purpose and placed in the field. In each of these experiments, there were three plots of tea each having 6 bushes with similar productivity. Two of these plots were covered by open-top chambers. One of the chambers in each experiment was supplied with $\mathrm{CO}_{2}$ from an external cylinder $\left(30 \mathrm{~kg}\right.$ of $\left.\mathrm{CO}_{2}\right)$. The $\mathrm{CO}_{2}$ level of the control plots was the ambient at $370 \mathrm{ppm}$ while that in the $\mathrm{CO}_{2}$ enriched chamber was maintained around $600 \mathrm{ppm}$. Due to financial constraints, $\mathrm{CO}_{2}$ enrichment had to be confined to only one chamber. The experiment at high elevation was conducted with the cultivar TRI 2005 and that at low elevation with the cultivar TRI 2027. At both locations, tea bushes were harvested at weekly intervals and the yield was recorded. Yield determinants (shoot density, shoot extension rate and weight of shoot), transpiration rate and net assimilation rates were also measured. The treatments were continued for a period of 18 months from September 2002 to March 2004.

Analysis of data and development of crop model: Relationships between environmental factors and tea yield were established by regression analysis. Effect of rainfall (moisture stress) on tea yield was first studied and then that of temperature was estimated excluding the effect of rainfall i.e. excluding the data for dry months (rainfall $<100 \mathrm{~mm}$ ). The loss of yield during periods of excess rainfall cou'd be partly attributed to reduced sunshine which is als: taken into account by the crop model. The relati unship between $\mathrm{CO}_{2}$ and yield was established using the data collected from the two field experiments. The analysis of rainfall data was performed separately for each agro-ecological region. The effect of temperature on tea yield was estimated by pooling the data from all the agro-ecological regions (AERs).

Development of the crop model: The crop model was developed based on methodologies used previously in growth simulation models for annual crops $^{8}$. In this exercise, it was assumed that climate change will have no effect on the availability of plant nutrients in tea lands as chemical fertilizers are extensively used in commercial plantations. The model parameters and their links are shown in Figure 1. In the presence of sun light, tea leaves produces carbohydrates; the total quantity of which is dependent up on the Radiation Use Efficiency of tea leaves (approximately $0.3 \mathrm{~g} / \mathrm{MJ}$ for a fully expanded leaf ${ }^{9}$ ) and Leaf Area Index (LAI) (approximately 5 for tea in plucking $\left.{ }^{10}\right)$. It is assumed that $60 \%$ of the total biomass 


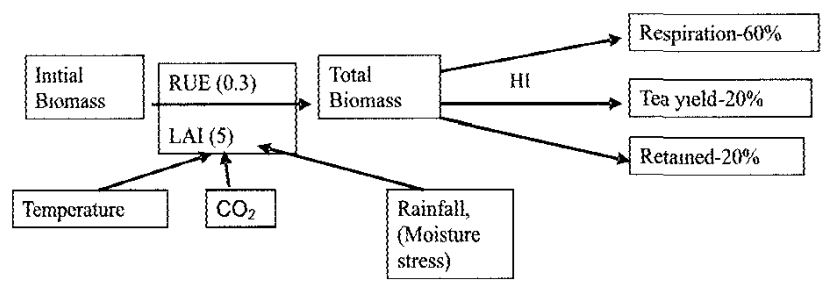

Radiation Use Efficiency: RUE

Harvest Index· HI

Leaf Area Index: LAI

Figure 1: Schematic diagram showing the parameters used for the crop model

produced by the tea bush is lost by respiration and about $20 \%$ is harvested (Harvest Index $=20 \%)^{11}$. The balance $20 \%$ is added to the biomass of the bush. The assimilation is influenced by the ambient temperature, ambient $\mathrm{CO}_{2}$ and rainfall. These climatic factors are expected to be affected by climate change. Although, the intensity of sun light (radiation) was necessary for running the model and yield predictions, there were no radiation data for tea growing regions. Therefore, it was approximately estimated by the relationship between the temperature difference (maximum-minimum) and solar radiation ${ }^{12}$.

The model was written in Fotran Simulation Translator (FST) and linked to the software package developed by the International Global Change Institute $(\text { IGCI })^{13}$, Waikato University, New Zealand. The crop model was run separately for each agro-ecological region as a site specific case because, the rainfall factor varied among the regions.

Testing sensitivity of the model and yield projections: The productivity under different climatic conditions was determined by linking the crop model into the software package developed by the IGCI. This software produces the future climatic scenarios, temperature change and rainfall change, corresponding to different climatic models also known as the General Circulation Models (GCM), and emission scenarios for different time slices. The climatic models used in this study were those developed in UK (HadCM3), Australia (CSIRO) and in Canada (CGCM). The two emission scenarios used were A1F1 with high emission and $\mathrm{B} 1$ with low emission ${ }^{14}$. By linking the crop model to this software, it was possible to obtain the crop yield as the output corresponding to future climatic conditions. The baseline and two climate change scenarios were used to run the model for each agroecological region and changes in yield were obtained. The software package also has the ability to interpolate the GCM climatic outputs into local values applicable to Sri Lanka. The sensitivity of the crop model for temperature, rainfall and $\mathrm{CO}_{2}$ were tested by changing each parameter separately and keeping others constant and studying the output or yield. Using the baseline values of rainfall, maximum and minimum temperatures as inputs, the yield predictions were made for the year 2050 under different emission scenarios. From these results, tea growing agro-ecological regions that were most vulnerable to climate change were identified. In addition, yield predictions were also made based on synthetic climate change scenarios (user defined scenarios) i.e. without using the GCM climatic outputs.

The base line tea productivity of different tea growing agro-ecological regions was obtained from the crop model by using the base line climatic data for each agro ecological region (average values for the period of 1961-1990).

\section{RESULTS AND DISCUSSION}

\section{Productivity trends}

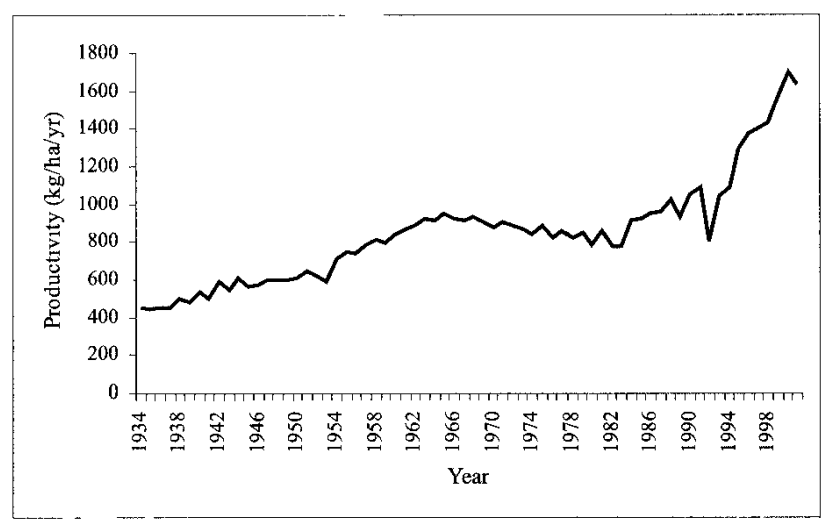

Figure 2: Annual variation of the productivity of tea lands in Sri Lanka

Figure 2 shows the annual variation of productivity of tea lands in Sri Lanka. Although, the productivity has been stagnating or slightly declining during the two decades of $1960-1980$ due mainly to the management changes (nationalization of estates) and poor inputs, there has been an overall increase in productivity from 1930s to date. There is a marked increase in productivity during the last two decades. This is mainly attributed to the expansion of new tea smallholdings with vegetatively propagated (VP) tea especially in the WL region where the productivity is comparatively higher than that of the old VP and seedling tea. The technological improvements such as introduction of high yielding cultivars and fertilizer inputs etc. have also contributed to this increase in overall productivity. However, a significant drop in productivity was observed in 1992 due to dry weather conditions. The resultant loss of tea production was about $26 \%$ compared to the previous year, that shows the magnitude of the impact of drought on tea yield. Figure 3 shows the variation of the drought effect in different tea growing regions. 
Accordingly, the loss of productivity had varied from about $14 \%$ in the IM region to about $28 \%$ in the IU region.

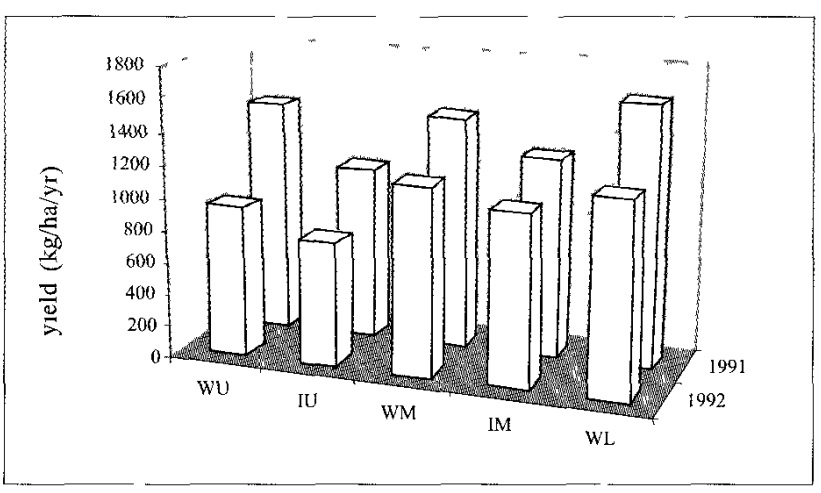

Figure 3: Effect of drought (1992) on the productivity of tea lands in different AERs in Sri Lanka (WL-Wet zone Low country, WM-Wet zone Mid country, IM-Intermediate zone Nid country, WU-Wet zone Up country and IU-Intermediatc zone Up country)

\section{Relationship between environmental factors and yield (productivity) of tea}

\section{a). Rainfall and dry weather}

In the series of analysis of monthly tea yield $(\mathrm{kg} / \mathrm{ha})$ and rainfall of each estate, it was found that there was a polynomial relationship between these two parameters when lag period of one month is considered i.e. rainfall of the previous month relates to the productivity of the current month (Figure 4). The low yield at very high rainfall regimes was attributed to the lack of sun shine. Therefore, a linear relationship between rainfall of the previous month and yield up to the optimum rainfall was established for each estate to estimate the effect of moisture stress on productivity and the optimum rainfall (Figure 5). The mean values of the optimum rainfall and the dependence (change of productivity, $\mathrm{kg} / \mathrm{ha} / \mathrm{mon}$ th per $\mathrm{mm}$ of rainfall below the optimum) of selected estates in a particular agro-ecological region were calculated and are given in Table 2. Accordingly, the optimum rainfall varied from about $223 \mathrm{~mm} / \mathrm{month}$ in the WU region to about $417 \mathrm{~mm} /$ month in the WM region. Of these two regions, the soil properties, mainly soil organic carbon content in the WU region, were reported to be better than that in the WM region ${ }^{15}$. These results show that the tea growing regions with poor soil conditions need more rainfall than those with good soils for a higher productivity. It is also well known that water holding capacity of soils is greatly determined by soil physical parameters. Soils with a poor structure and less organic matter have low water holding capacity.

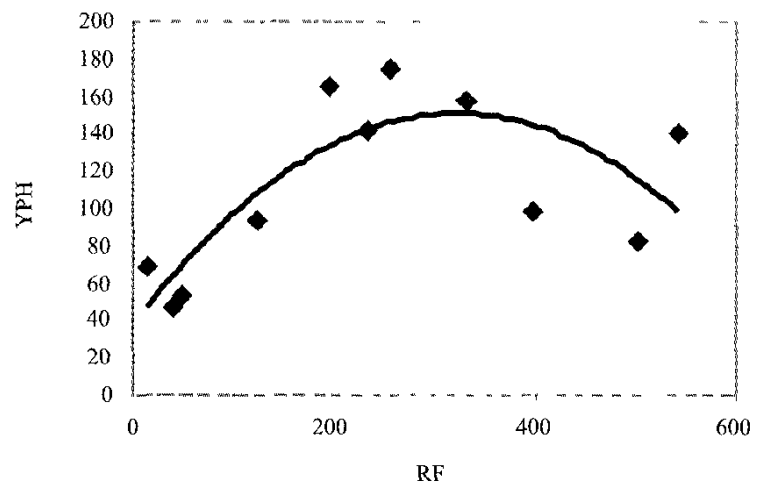

Figure 4: Relationship between rainfall of the previous month, $\mathrm{RF}(\mathrm{mm})$ and productivity YPH $(\mathrm{kg} / \mathrm{ha} / \mathrm{month})$ of Noragalla estate, WL

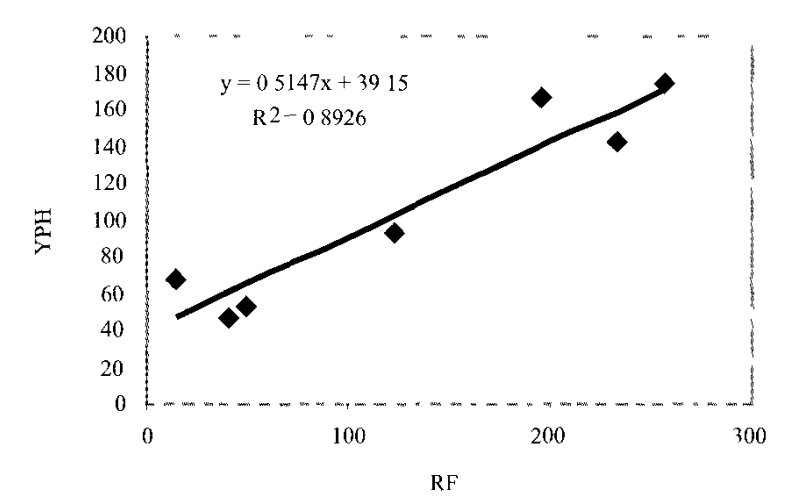

Figure 5: Linear relationship bctween rainfall of the previous month, RF (mm) and productivity YPH ( $\mathrm{kg} / \mathrm{ha} /$ month) of Noragalla estate, WL up to the optimum rainfall only

Table 2: Optimum monthly rainfall and effect of rainfall on productivity; $M$ (change of productivity $\mathrm{kg} / \mathrm{ha} / \mathrm{month}$ per $\mathrm{mm}$ of rainfall) in the five AERs (Wet zone Low country-WL, Wet zone mid country-WM, Intermediate zone Mid country-IM, Wet zonc Up country-WU and Intermediate zone Up country-IU).

\begin{tabular}{ccc}
\hline Region & $\begin{array}{c}\text { Optimum rainfall } \\
(\mathrm{mm} / \text { month })\end{array}$ & Effect of Rainfall-M \\
\hline WL & $350 \pm 20$ & $0.29 \pm 0.03$ \\
WM & $417 \pm 49$ & $0.36 \pm 0.06$ \\
IM & $227 \pm 10$ & \\
WU & $223 \pm 38$ & $0.81 \pm 0.11$ \\
IU & $303 \pm 34$ & $0.55 \pm 0.07$ \\
\hline
\end{tabular}




\section{b). Ambient temperature}

The ambient temperature varies with elevation and the variation was minimal within an agro-ecological region when compared with that between two regions. Therefore, data from all regions were pooled together to get a wider range of temperatures and study the temperature influence on tea yield. As discussed elsewhere, the temperature effect on productivity was determined by regression analysis between temperature and productivity data excluding that of dry months. The trend line on the effect of temperature on tea yield (Figure 6) shows that the optimum temperature giving the highest yield was found to be around $22^{\circ} \mathrm{C}$. High variation observed among the data points was attributable to the site variations in soil, cultivar and age etc. Under controlled environmental conditions, scientists have found that the growth of tea is linearly related to temperature ${ }^{2,6,9}$. Therefore, linear functions between temperature and productivity were established below and above the optimum temperatures for estimating the temperature effect for modeling purposes.

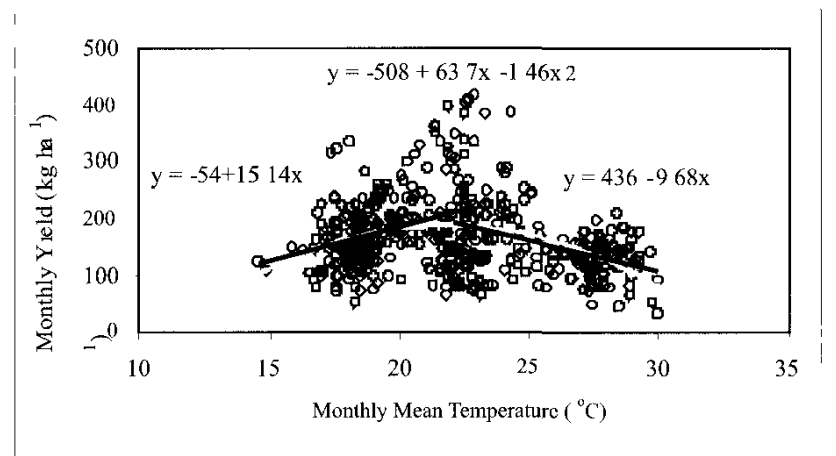

Figure 6: Relationship betwcen ambient temperature and monthly tea yield Polynomial relationship and linear relationships below and above the optimum temperature $\left(22^{\circ} \mathrm{C}\right)$ are shown separately\}

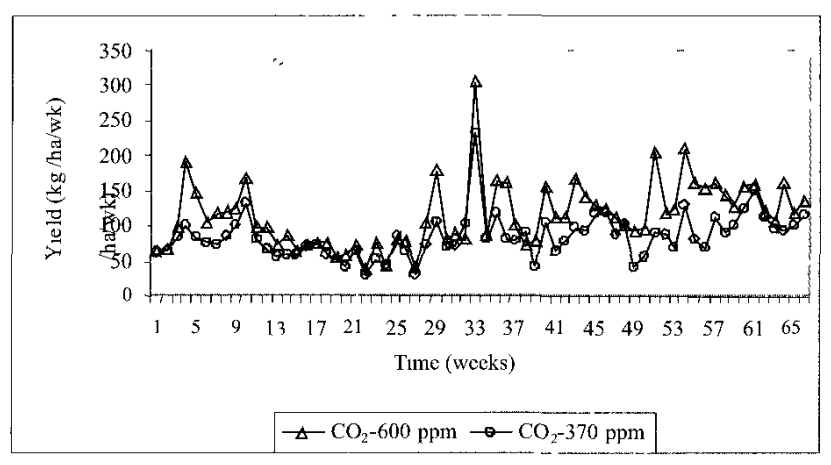

Figure 7: Effect of $\mathrm{CO}_{2}$ on made tea yield at low elevation (Ratnapura-WL)

\section{c). Ambient Carbon Dioxide $\left(\mathrm{CO}_{2}\right)$}

Results of the two field experiments showed that the productivity of tea bushes increased at high $\mathrm{CO}_{2}(600 \mathrm{ppm})$ concentrations at both elevations (WL \& WU). The increase in yield was about 33 and $37 \%$ in the high and low elevations (Figure 7), respectively. As there was no significant difference between these two locations in the yield response to $\mathrm{CO}_{2}$, the mean value of $35 \%$ was used for the development of the crop model. Long term data from the experiments showed that the increase in yield with enhanced $\mathrm{CO}_{2}$ was a result of high shoot population density and shoot weight supported by high net assimilation rate and water use efficiency of tea leaves in comparison with the current level of ambient $\mathrm{CO}_{2}$ concentration (control) ${ }^{16}$. It was observed during the measurement of net assimilation rate that there was no clear difference in the ambient temperature between two $\mathrm{CO}_{2}$ levels.

\section{Development and testing the sensitivity of the crop model}

The effects of temperature, rainfall (moisture stress) and $\mathrm{CO}_{2}$ on the productivity of tea lands were estimated by the crop model as given in the following functions.

\section{$\mathrm{CO}_{2} \operatorname{effect}(\mathrm{CO} 2 E F F)$}

CO2EFF $=(\mathrm{CO} 2-370) * 0.00122$

\section{Temperature effect $(T E F F)$}

TEFF $=(22-M E A N T)^{*} 15.14$; when MEANT is less than $22^{\circ} \mathrm{C}$ TEFF $=\left(\right.$ MEANT - 22)*9.68; when MEANT is higher than $22^{\circ} \mathrm{C}$

\section{Rainfall Effect $(R F E F F)$}

\section{$R F E F F=R_{F F}^{*}(O R A I N F-R A I N F)$}

Where $\mathrm{CO} 2$ is the ambient $\mathrm{CO}_{2}$ level (ppm), MEANT is the monthly mean temperature $\left({ }^{\circ} \mathrm{C}\right)$ of the location, $\boldsymbol{R F F}$ is the change of productivity per $\mathrm{mm}$ change of rainfall below the optimum rainfall for the AER ( $\mathrm{kg} / \mathrm{ha} / \mathrm{month} /$ $\mathrm{mm}), \boldsymbol{O R A I N F}$ is the optimum rainfall for the AER (mm) and $\boldsymbol{R A I N F}$ is the monthly total rainfall $(\mathrm{mm})$ of the location. Rainfall effect is calcuated if RAINF is less than ORAINF only.

Four locations representing the four agro-ecological regions, WU (Nuwara Eliya), IU (Passara), WM (Kandy) and WL (Ratnapura) with long term weather records were selected to carry out the sensitivity analysis. The yield predictions were made using synthetic climate scenarios viz. increase in temperature by $1 \& 2^{\circ} \mathrm{C}$, variation (increase and decrease) in rainfall by $10 \%$ and increase in $\mathrm{CO}_{2}$ 
Table 3: Tea yields at four locations projected by the synthetic scenarios (increase in temperature by $1 \& 2{ }^{\circ} \mathrm{C}$, increase in rainfall by $10 \%$, decrease in rainfall by $10 \%$ and increase in ambient $\mathrm{CO}_{2}$ level to $435 \mathrm{ppm}$ ) for the year 2050

\begin{tabular}{ccccccc}
\hline $\mathrm{CO}_{2}(\mathrm{ppm})$ & $\begin{array}{c}\text { Rainfall } \\
\text { Change }(\%)\end{array}$ & $\begin{array}{c}\text { Temperature } \\
\text { Change }\left({ }^{\circ} \mathrm{C}\right)\end{array}$ & Ratnapura & Kandy & N'Eliya & Passara \\
\hline 370 & 0 & 0 & 2489 & 2217 & 2454 & 2651 \\
370 & 0 & 1 & 2282 & 2177 & 2651 & 2569 \\
370 & 0 & 2 & 2070 & 2117 & 2760 & 2469 \\
370 & -10 & 0 & 2456 & 2161 & 2418 & 2591 \\
370 & 10 & 0 & 2482 & 2305 & 2480 & 2749 \\
435 & 0 & 0 & 2710 & 2695 & 3035 & 3080 \\
435 & 0 & 1 & 2502 & 2567 & 3035 & 2998 \\
\hline
\end{tabular}

Table 4: Tea yields at four locations projected for the year 2050 by the GCM attached to the IGCI software package

\begin{tabular}{lccc}
\hline \multirow{2}{*}{ Model } & \multicolumn{3}{c}{ Yield (kg/ha/yr) } \\
\cline { 2 - 4 } Baseline & Ratnapura & Kandy & N'Eliya \\
\cline { 2 - 4 } CGCM-A1F1 & 2489 & 2217 & 2454 \\
CGCM-B1 & 2314 & 2217 & 3108 \\
HadCM3-A1F1 & 2380 & 2228 & 3072 \\
HadCM3-B1 & 2348 & 2174 & 3130 \\
CSIRO-A1F1 & 2419 & 2189 & 3115 \\
CSIRO-B1 & 2401 & 2246 & 3167 \\
\hline
\end{tabular}

concentration up to $435 \mathrm{ppm}$ keeping in line with the global predictions for 2050 . Results of the analysis are given in Table 3 . In order to analyze the combined effects of selected parameters, the tea yield was also projected for the year 2050 using the downscaled climate projections corresponding to the three climatic models and emission scenarios referred to earlier (IGCI software package), and the results are given in Table 4.

Results in Table 3 show that increase in temperature alone by $1{ }^{\circ} \mathrm{C}$ is likely to reduce the yields at IU, WM and WL regions and a greater reduction in the productivity is predicted under a temperature rise by $2^{\circ} \mathrm{C}$. In contrast, tea plantations in WU region will have beneficial effects of warmer climatic conditions. Increase in annual rainfall by $10 \%$ will increase tea yield in all tea growing regions except in WL. In contrast, a lower yield can be expected if rainfall is reduced by $10 \%$. Analysis of results also showed that increase in ambient $\mathrm{CO}_{2}$ concentration will increase yield in all tea growing regions. Further, high $\mathrm{CO}_{2}$ concentration together with temperature rise will results in higher productivity in all the regions. This positive effect is remarkably less in the WL region where the warmest climate is prevalent at present. It suggests that the beneficial effect of $\mathrm{CO}_{2}$ fertilization is reduced by rising temperatures above optimum at low elevations. Even though the yield reported in Table 3 is not absolute, these results represent the direction in which the future productivity of tea lands is likely to change.

The combined effect of varying climatic factors including $\mathrm{CO}_{2}$ on tea yield at three elevations is given in Table 4. These results reveal that in the long term, climate change may bring negative effects at the low elevations (Ratnapura). The tea plantations at high elevation (Nuwara Eliya) seem to receive beneficial effects. Of the three climate models, two (CSIRO and CGCM) have predicted an increasing trend in production in the mid elevations while the third; HadCM3 shows a decreasing trend. This is because of the higher temperature projections given by the HadCM3, compared to the other two, resulting in the downscaled temperatures exceeding the optimum value for tea yield.

\section{Adaptation measures}

Although $\mathrm{CO}_{2}$ fertilization can enhance productivity of tea plantations, the beneficial effect seems to be masked by the rising temperatures and dry weather conditions in the majority of tea plantations, mainly at low elevations when compared to the other two. Hence, it will be necessary to implement suitable adaptation measures with proven cost-benefits to minimize such adverse effects of global warming and harness maximum benefits of $\mathrm{CO}_{2}$ rise. Some of the "no regret strategies" which could be implemented to minimize adverse consequences of rising temperatures above optimum in regions WL, WM and IU and of dry weather should be aimed at improving crop, soil and aerial environmental conditions. Nevertheless, very low yielding tea lands with poor soil conditions are preferred to be diversified into fuel wood or timber plantations. Such plantations can be advantageously used for carbon trading in the years to come. Marginal tea lands can also be converted to 'thatch banks' (planting of rehabilitation grasses) and used as a source of green manure for improving soils in the potential tea fields. 
Use of drought tolerant cultivars and grafted plants with drought tolerant characteristics in drought prone regions and intercropping tea with other tree crops (cash crops) such as rubber and coconut are among the most suitable adaptation measures. High intensity intercropping systems will reduce the ambient temperature around tea bushes and also increases the land utilization efficiency ensuring better returns ${ }^{17}$.

Soil improvements aimed at soil and soil moisture conservation, addition of organic matter and reducing soil temperature, minimize adverse effect of dry weather and high temperatures. They include soil conservation measures, in situ generation of compost and incorporation into soil, establishment of SALT (Sloping Agriculture Land Technology) hedge rows, envelope forking (loosening the soil without turning), burying of prunings, mulching in young tea and irrigation. Experimental results have shown that the increase in soil organic carbon by $1 \%$ could increase annual yield by about $400-500 \mathrm{~kg} / \mathrm{ha}^{18}$. Irrigation also increases tea yield by about $50-100 \%$. The yield response to fertigation i.e. irrigation with fertilizer, can be as high as $300 \%$ during dry weather ${ }^{19}$.

Planting and management of a good stand of shade trees reduces ambient temperature, increase relative humidity and adds organic carbon to soil ${ }^{20}$. Shade trees in tea lands can reduce ambient temperature by about $2-3^{\circ} \mathrm{C}$ thus attenuating the adverse effects of higher temperatures on growth of tea especially in the low elevations.

\section{CONCLUSION}

The productivity of tea lands is greatly influenced by environmental factors. As a result of global warming, agriculture is predicted to be greatly affected. Therefore, a study was undertaken in collaboration with the Meteorological Department of Sri Lanka to assess the impact of climate change on productivity of tea plantations in Sri Lanka. The study resulted in the following conclusions.

1. The optimum temperature for cultivation of tea was found to be about $22^{\circ} \mathrm{C}$.

2. Reduction of rainfall by $100 \mathrm{~mm}$ per month was found to reduce the productivity by $30-80 \mathrm{~kg}$ of 'made' tea/ha/month in different regions. The optimum rainfall for tea cultivation varied from 223 to $417 \mathrm{~mm}$ per month.

3. Increase in ambient $\mathrm{CO}_{2}$ concentration from the current level (around $370 \mathrm{ppm}$ ) to $600 \mathrm{ppm}$, will increase tea yield by about $33-37 \%$.

4. Yield projections for the year 2050 given by the crop model based on synthetic scenarios showed that increasing temperatures are likely to reduce tea yields in $\mathrm{IU}, \mathrm{WM}$ and $\mathrm{WL}$ regions while increasing the yield in WU region.

5. Reduction in rainfall reduces the yield in all tea growing regions. Although increase in $\mathrm{CO}_{2}$ increases tea yield, this effect of $\mathrm{CO}_{2}$ fertilization is nullified by high temperatures at low elevations.

6. The GCM based climate scenarios also predict that tea yields are likely to increase at high elevations due to climate change. In contrast, the productivity of tea plantations at low elevations are likely to be reduced. As low and mid elevations are more vulnerable to the adverse impact of climate change, growers need to pay more attention to implement adaptation measures to minimize such adverse effects.

\section{Acknowledgement}

The research reported in this paper was supported by grant number AS12 from Assessment of Impact and Adaptation to Climate Change (AIACC), a project that was funded by the Global Environment facility, the US Agency for International Development, the Canadian International Development Agency, and the US Environment Protection Agency implemented by the United Nations Environment Programme and executed by the Global Change SysTem for Analysis Research and training (START) and the Third World Academy of Sciences (TWAS). Technical support was given by the Indian Agricultural Research Institute (IARI), New Delhi and IGCI, University of Waikato, New Zealand.

\section{References}

1. Anonymous (1994). Climate change in Asia. Sri Lanka Country Report. Asian Development Bank. Colombo.

2. Wijeratne M.A. \& Fordham R. (1996). Effect of environmental factors on growth and yield of tea (Camellia sinensis L.) in the low country wet zone of Sri Lanka. Sri Lanka Journal of the Tea Science 64:21-34.

3. Kandiah S. \& Devadasan T. (1980). Quantification of weather parameters to predict tea yields. Tea Quarterly 49: 25-33.

4. Devanathan M.A.W. (1976). The quantification of climatic constraints on plant growth. Tea Quarterly 45: 43-72.

5. Mathews R.B. \& Stephens W. (1998). CUPPA-Tea. A simulation model describing seasonal yield variation and potential production of tea. II. Biomass production and water use. Experimental Agriculture 34: 369-389.

6. Wijeratne M.A. (1996). Vulnerability of Sri Lankan tea plantations to global climate.change. Water, Air and Soil Pollution 92: 87-94.

7. Modder W.W.D. \& Wijeratne M.A. (2002). Plantation agriculture and mechanization. A review of needs and prospects Journal of the National Institute of Plantation Management 18: 1-9. 
8 Kalra N \& Aggrawal PK (1996) Evaluating the growth response for wheat under varying inputs and changing climate options using Wheat Growth Simulator WTGROWS In Chmate Varabihy and Agnculture (Eds YP Abrol, S Gadgl \& GB Pant) pp 320338 Narosha Publrshing House, New Delhi

9 Carr M K V \& Stephens W (1992) Climate weather and the yield of tea (In Tea Cultwation to consumpuon (Eds K C Willson \& M N Chfford) pp 87-135 Chapman Hall, London

10 Banergee B (1992) Botanicd classification of tea In Tea. Cultuation to consumption (Eds K C Willson \& M N Clifford) pp 25-51 Chapman Hall, London

11 Barbord A C \& Barua D N (1988) Respiratory losses and partitioning of assimilates in tea bushes (Camellia sinensis L ) under plucking Two and a Bud 35 75-82

12 Hargreaves G H \& Samanı Z A (1982) Estımatıng potential evapotranspiration Journal of Irrigation and Drainage Engineering 108 225-230

13 Warrıck R A, Kenny G J , Sims G C , Erıcksen N J , Ahmad Q K \& Mirza M Q (1996) Integrated model system for natıonal assessment of climate change applications in New Zealand and Bangladesh Journal of Water, Atr and Soll Pollution 92 1-2, 221-227

14 IPCC (2000) Special report on emission scenarios $A$ special report of working group III of the
Intergoi ernmental Panel on Clmate Change Cambndge University Press, UK

15 Amarathunga M K S L D, Wyeratne M A \& Jayaratnc K PS C (2001) Impact of variation of sol properties on the bush stand and productivity of tea lands in Sir Lanku Proceedings of the $57^{\text {ih }}$ Annual session Part 1 Abstracts, Sn Lanka Associdtion for the Advancement of Science (SLAAS), Colombo

16 Wijerdtne $\mathrm{MA}$, Ratnasirı J \& Premathunga E W T P (2007) Effect of CO2 fertilization on growth and yicld of mature tea in the low country wet zone of Sri Lanka Journal of Plantation Crops (Accepted for puplication)

17 Jayakody A \& Shyamal1e H W (2002) Cost of tea cultwation from nursery to the field p 57 Ted Research Institute of Srı Lanka, St Coomb's Estate, Taldwakelle

18 Amarathunga M K S L D \& Wijeratne M A (2000) Some of the ecological factors affecting sustainable productivity of clonal tea Proceedings of the 200 th Experiment and Extension Forum, January 28, 2000 pp 515 The Ted Research Instıtute of Srı Lanka, St Coomb's Estate, Talawakelle

19 Annual Reports (2001 \& 2002) Reports of the Agronomy Divisıon, Tea Research Instıtute of Srı Lanka, St Coomb's Estate, Talawakelle

20 Sivapalan P (1993) Shade and green manure trees in ted a holıstıc appraisal Sri Lanka Journal of Tea Scıence $\mathbf{6 2}$ $41-46$ 